\title{
Contrast effect in the interview
}

\author{
ALLEN J. SCHUH \\ Department of Management Sciences, California State University, Hayward, California 94542
}

\begin{abstract}
Employment interviewers $(\mathrm{N}=120)$ and managers $(\mathrm{N}=180)$ viewed videotaped interviews of four MBA applicants for a management trainee position and evaluated them on a dichotomous criterion. The change-over sequence design method was used to analyze for a contrast effect in the three counterbalanced treatment conditions. Three anchor stimuli preceded the target stimulus as in the traditional contrast paradigm. Results confirmed the presence of a contrast effect $[\mathrm{F}(2,596)=34.57, \mathrm{p}<.01]$. The findings indicated a greater contrast effect when averaged over the three anchor stimuli $\left(\omega^{2}=.065\right)$ than with the target stimulus $\left(\omega^{2}=.037\right)$, where it was also significant $[\mathrm{F}(2,294)=5.91, \mathrm{p}<.01]$. Adaptation explains the diminished contrast effect over successive judgments. The contrast effect rivals applicant level $\left(\omega^{2}=.087\right)$ in importance.
\end{abstract}

Researchers who have examined the impact of decision errors on the evaluations made in the interview setting have spent a substantial portion of their effort on the contrast effect (Hakel, Ohnesorge, \& Dunnette, 1970; Landy \& Bates, 1973; Rowe, 1967; Wexley, Yukl, Kovacs, \& Sanders, 1972).

While, on the one hand, we might cite the accuracy of evaluations by showing that about $80 \%$ of the total variance is attributable to applicant qualifications (Hakel et al., 1970; Landy \& Bates, 1973), one could also show reports that the contrast effect can account for up to $80 \%$ of the variance (Wexley et al., 1972). And Rowe (1967) warned that the contrast effect may account for more variance than applicant qualifications. These results are far too discrepant to remain unaddressed in further research.

This research was specifically designed to examine a neglected aspect of the problem: What effects are operating between the anchor stimuli presented as a frame of reference prior to presentation of the target stimulus? The possibility that the contrast effect adapts (Helson, 1964) over the presentation of the anchor stimuli has not been investigated. The investigators who failed to find a sizable contrast effect with 2 anchors (Hakel et al., 1970) increased the number to 4 (Leonard \& Hakel, Note 1) or even 11 (Landy \& Bates, 1973). The anchor stimuli themselves should have been investigated.

The interviewer from the personnel department performs a prescreening function. The task is one of reviewing the qualifications of applicants for a position opening and screening out those who do not represent the minimum qualifications. Those applicants who survive the screening by the employment interview are then reviewed by the managers and, from these candi-

The author expresses his gratitude to William L. Sawrey, the National Association of Mutual Savings Banks, and the Institute of Research and Business Development. Requests for reprints should be sent to Allen J. Schuh, Department of Management Science, California State University, Hayward, California 94542. dates, some are hired. Managers and employment interviewers are likely to see their job functions differently. The difference in perceived job function may manifest itself in either more harsh or lenient selection decisions.

A variety of dependent variables has been used in the prior research in this area, all except the one that interviewers and managers are most familiar with and, indeed, to which they are usually restricted. The criterion measure in this experiment was a pass-fail decision. Thus, the setting was more realistic and the judgment required more appropriate for transfer of the research findings back to actual hiring situations.

\section{METHOD}

\section{Subjects}

There were two groups of participants: professional employment interviewers $(N=120)$ in the San Francisco Bay area, and branch managers $(\mathrm{N}=180)$ of banks in the northeastern United States. The interviewers were enrolled in a management development program focusing on the interview and performance evaluation. The managers were enrolled in a management development program to review general management skills.

\section{Procedure}

Participants were divided into treatment conditions, where they were shown only one of three possible orders of applicants: $A B C D, B C A D$, or $C A B D$. The interviewers and managers watched four videotaped interviews of applicants who were applying for a management trainee position. They were permitted to refer to evaluation guides. Each of the four applicants was asked the same 11 questions in a structured interview that lasted about $10 \mathrm{~min}$.

After each interview, the subjects were given $5 \mathrm{~min}$ to complete the evaluation guide and make an overall suitability judgment of whether to go further or stop employment negotiations. This is the same dichotomous decision that the professionals were familiar with in their evaluations outside the experimental setting.

On the videotape, the applicants were shown seared behind a table answering questions asked by an off-camera interviewer. Each applicant was completing the requirements for a Masters Degree in Business Administration. Applicants were male, about 30 years old, married, veterans of military service, and had been active in student government. 


\section{RESULTS}

The presence of a significant contrast effect on the target stimulus was evaluated with a two-way analysis of variance containing three orders $(\mathrm{ABC}, \mathrm{BCA}$, and $\mathrm{CAB}$ ) and two participant groups (interviewers and managers). Results indicated that the target stimulus (D) was affected by order $[\mathrm{F}(2,294)=5.91, \mathrm{p}<.01$, $\left.\omega^{2}=.037\right]$. Other effects were not significant.

A two-way analysis of variance was performed on the anchors. The two participant groups were pooled for this analysis. There were three orders (ABC, BCA, and $\mathrm{CAB}$ ) and three applicants (A, B, and $\mathrm{C}$ ) for analysis. $\mathrm{Li}$ $(1964$, p. 207) recommends the change-over sequence design technique for this situation. It was found that the applicants differed significantly $[\mathrm{F}(2,596)=45.62$, $\left.\mathrm{p}<.01, \omega^{2}=.087\right]$. The order (contrast) effect was also significant $\left[\mathrm{F}(2,596)=34.57, \mathrm{p}<.01, \omega^{2}=.065\right]$. The estimate of $\omega^{2}$ was calculated from the formula given in Hays (1973, p. 487).

The percentage of raters who indicated each applicant was acceptable for further employment evaluation was calculated. The data are presented by treatment condition ( $\mathrm{ABCD}, \mathrm{BCAD}$, and $\mathrm{CABD}$, respectively) to indicate the chances of being rated as acceptable depending upon the order in which the applicant was seen: Applicant A, 91, 91, and 87; Applicant B, 55, 86, and 28; Applicant C, 51, 73, and 78; Applicant D, 44, 24, and 45 . These data show that the rating is highest for each applicant when seen first. The percentage varies little (4\%) for Applicant A, the best qualified applicant. but considerably (58\%) for Applicant B, who is perceived as less qualified. The rating of Applicant D, who always appeared in the fourth position, varied 21 percentage points depending upon whether he was seen immediately after A or B.

\section{DISCUSSION}

The impact of the contrast effect is greatest early in the series of anchor stimuli; later in the series the contrast effect will have largely adapted. This research would suggest that if the applicants are seen singly, they will be given lenient evaluations; if seen as couplets, the contrast effect may be dramatic; if seen in groups of more than four, the contrast effect will diminish. When possible, applicants should be seen in groups.

This research used two groups of professionals, but both groups gave the same evaluations despite wide variation in responsibilities for hiring. The interviewers were from the same metropolitan area but hired for diverse jobs, while the managers were geographically dispersed but had a common role perception of the job requirements of management trainee in a bank. Nevertheless, these two groups of professionals came to the same decisions in this study.

The contrast effect is an important systematic source of error variance in the interview setting. Averaged over the three anchor stimuli, the contrast effect accounted for $6.5 \%$ of the variance. Applicant level accounted for only $8.7 \%$ of the variance. It is because contrast effect accounts for almost as much variance as applicant level that attempts to reduce its impact are so crucial to reliability and validity in the interview setting.

\section{REFERENCE NOTE}

1. Leonard, R. L., \& Hakel, M. D. Contrast and assimilation effects in an employment setting: $A$ theoretical re-interpretation. Paper presented at the meeting of the Midwestern Psychological Association, Detroit, May 1971.

\section{REFERENCES}

Hakel, M. D., Ohnesorge, J. P., \& Dunnette, M. D. Interviewer evaluations of job applicants' resumes as a function of the qualifications of the immediately preceding applicants: An examination of contrast effects. Journal of Applied Psychology, 1970, 54, 27-30.

Hays, W. L. Statistics for the social sciences. New York: Holt, Rinehart, \& Winston, 1973.

Helson, H. Adaptation-level theory: An experimental and systematic approach to behavior. New York: Harper \& Row, 1964.

LANDY, F. J., \& Bates, F. Another look at contrast effects in the employment interview. Journal of Applied Psychology, 1973, 58, 141-144.

LI, C. C. Introduction to experimental statistics. New York: McGraw-Hill, 1964.

RowE, P. M. Order effects in assessment decisions. Journal of Applied Psychology, 1967, 51, 170-173.

WeXIeY, K. N., YUKL, G. A., Kovacs, S. Z., \& SANDERS, R. E. Importance of contrast effects in employment interviews. Journal of Applied Psychology, 1972, 56, 45-48.

(Received for publication December 27, 1977.) 